\title{
Association of the Extent of Atrophic Gastritis With Specific Dyspeptic Symptoms
}

\author{
Sook Hee Chung, ${ }^{1}$ Kwang Jae Lee, ${ }^{1 *}$ Ja Yeon Kim, ${ }^{2}$ Seon Gyo Im, ${ }^{1}$ Eunkyung Kim, ${ }^{1}$ Min Jae Yang, ${ }^{1}$ and Seo Hee Ryu ${ }^{1}$ \\ ${ }^{1}$ Department of Gastroenterology and ${ }^{2}$ Office of Biostatistics, Ajou University School of Medicine, Suwon, Gyeonggido, Korea
}

\begin{abstract}
Background/Aims
It remains unclear whether atrophic gastritis can affect dyspeptic symptoms. We aimed to investigate whether the extent of atrophic gastritis is associated with specific dyspeptic symptoms.
\end{abstract}

\section{Methods}

Consecutive adults in a routine health-checkup program were enrolled in the study. The extent of atrophic gastritis was classified into 3 groups based on the Kimura-Takemoto criteria; the gastritis with no or little atrophy (group A: C0), the gastritis with atrophy mainly in the antrum (group B: C1 and C2), and the gastritis with atrophy in the large area of the corpus (group C: C3 and O). Upper gastrointestinal symptoms were categorized into "typical reflux symptoms," "epigastric pain syndrome (EPS)-related symptoms," and "postprandial distress syndrome (PDS)-related symptoms."

\section{Results}

A total of 1827 patients (1009 males, mean age 45.1 years) were included in the analysis. The subgroups of atrophic gastritis were as follows: group $A(n=1218,66.7 \%)$, group $B(n=392,21.4 \%)$, and group $C(n=217,11.9 \%)$. Typical reflux, EPS-related, and PDS-related symptoms were present in 10.5\%, $19.8 \%$, and $16.2 \%$ of the subjects, respectively. PDS-related and EPS-related symptoms were significantly more prevalent in the group C of male patients and the group B of female patients, respectively, compared with other groups. PDS-related and EPS-related symptoms were independently associated with the group $C$ in males $(O R, 2.123 ; 95 \% \mathrm{Cl}, 1.090-4.136)$ and the group $B$ in females $(O R, 2.571 ; 95 \% \mathrm{Cl}, 1.319-5.025)$, respectively.

\section{Conclusions}

The extent of atrophic gastritis appears to affect the generation of specific dyspeptic symptoms in a gender-dependent manner. (J Neurogastroenterol Motil 2015;21:528-536)

Key Words

Atrophic gastritis; Dyspepsia; Epigastric pain syndrome; Postprandial distress syndrome

Received: May 5, 2015 Revised: June 18, 2015 Accepted: July 15, 2015

(c) This is an Open Access article distributed under the terms of the Creative Commons Attribution Non-Commercial License (http://creativecommons. org/licenses/by-nc/4.0) which permits unrestricted non-commercial use, distribution, and reproduction in any medium, provided the original work is properly cited.

${ }^{*}$ Correspondence: Kwang Jae Lee, MD, PhD

Department of Gastroenterology, Ajou University Hospital, Ajou University School of Medicine, 164 Worldcup-ro, Yeongtong-gu, Suwon 16499, Korea

Tel: +82-31-219-5102, Fax: +82-31-219-5999, E-mail: kjleemd@hotmail.com

Financial support: None.

Conflicts of interest: None.

Author contributions: Sook Hee Chung acquired data, analyzed data, and wrote the paper; Seon Gyo Im, Eunkyung Kim, Min Jae Yang, and Seo Hee Ryu acquired data; Ja Yeon Kim participated in statistical analysis; Kwang Jae Lee made the concept of the study, analyzed data, wrote the paper, and revised the manuscript. All authors approved the final version of the article, including the authorship list. ORCID: Kwang Jae Lee, http://orcid.org/0000-0002-8534-0850. 


\section{Introduction}

Upper gastrointestinal symptoms are common in the general population. ${ }^{1,2}$ Dyspepsia refers to a symptom or group of symptoms that is likely to originate from the gastroduodenal region. Dyspeptic symptoms can be further subdivided into meal-related dyspeptic symptoms, which are characterized by postprandial fullness or early satiation, and meal-unrelated dyspeptic symptoms such as epigastric burning or epigastric pain. ${ }^{3}$ The organic causes of dyspeptic symptoms, such as peptic ulcers and malignant lesions, can be detected using upper gastrointestinal endoscopy. However, most dyspeptic patients have no such organic abnormalities, and are considered to have functional dyspepsia. According to the Rome III criteria, functional dyspepsia is defined as the presence of symptoms that are thought to originate from the gastroduodenal region, in the absence of any organic, systemic, or metabolic disease that is likely to explain the symptoms. ${ }^{3}$

Abnormal gastric motility such as delayed gastric emptying, impaired proximal gastric accommodation to a meal and visceral hypersensitivity such as gastric hypersensitivity to distension and hypersensitivity to acids are generally considered to be the main pathophysiologic mechanisms inducing dyspeptic symptoms in functional dyspepsia. ${ }^{3}$ Excessive secretion of gastric acid has been suggested to be involved in the pathogenesis of functional dyspepsia, because proton pump inhibitors are effective for treating dyspepsia in some patients. ${ }^{4-9}$ However, previous reports regarding the levels of gastric acid secretion in dyspeptic patients showed controversial results. ${ }^{6,10,11}$ Furthermore, atrophic gastritis is common in the general population of South Korea and Japan where Helicobacter pylori infection is highly prevalent. The extent or grade of atrophic gastritis may influence on the level of gastric acid secretion. Particularly, advanced atrophy involving the gastric corpus and fundus can reduce pepsin and ghrelin secretion as well as acid output, whereas, atrophic gastritis of the antral mucosa can lead to a reduced number of somatostatin-secreting D cells, resulting in an increase of acid output. ${ }^{12}$ Although these alterations of gastric physiology appear to contribute to the genesis of dyspeptic symptoms, data regarding the relationship between atrophic gastritis and specific dyspeptic symptoms are lacking.

Thus, the aim of the present study was to investigate whether the extent of atrophic gastritis is associated with specific dyspeptic symptoms.

\section{Materials and Methods}

\section{Subjects}

A total of 2831 consecutive adults (ages $>18$ years) undergoing esophagogastroduodenoscopy (EGD) in a routine healthcheckup program at the Health Promotion Center of Ajou University Hospital between January 2012 and December 2012 were enrolled prospectively in this study. The health-checkup program included EGD, abdominal ultrasound, and routine blood tests. The test for $H$. pylori infection was not routinely performed because the test and treat for $H$. pylori-infected subjects without endoscopic evidence of peptic ulcer is not generally accepted in South Korea. Subjects undergoing health checkups may or may not be symptomatic. All subjects were asked to com-

2831 Total subjects undergoing EGD in a routine health-screening program

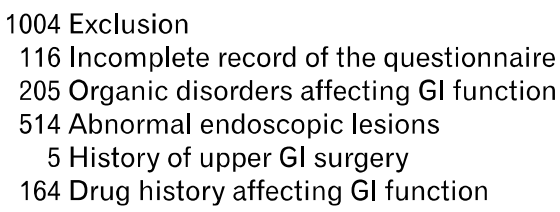

1004 Exclusion

116 Incomplete record of the questionnaire

205 Organic disorders affecting GI function

514 Abnormal endoscopic lesions

5 History of upper GI surgery

164 Drug history affecting Gl function

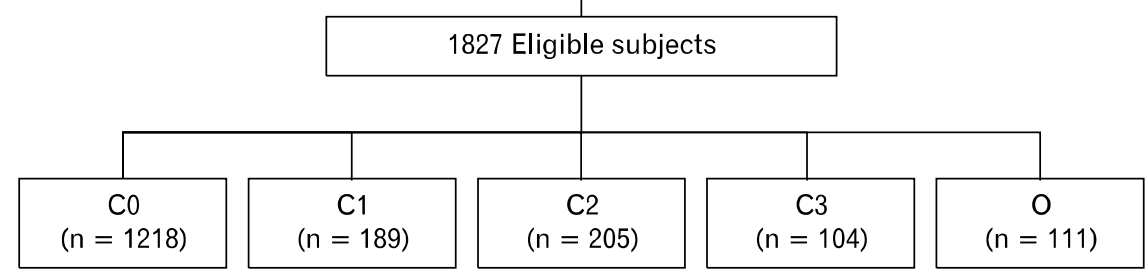

Figure 1. Inclusion and exclusion flow chart for enrollment of study participants. The extent of atrophic gastritis was classified as C0, C1, C2, C3, and O, based on the endoscopic classification system suggested by Kimura et al, ${ }^{13}$ and Suzuki and Moayyedi. ${ }^{14}$ EGD, esophagogastroduodenoscopy; GI, gastrointestinal. 
plete a symptom questionnaire before undergoing EGD. Those who had organic disorders influencing the function of the upper gastrointestinal tract, such as diabetes mellitus, severe liver disease, chronic renal failure, or severe pulmonary disease, were excluded. Subjects who had malignant, ulcerative, erosive, or acute mucosal lesions of the upper gastrointestinal tract; who did not complete the questionnaire; who had a history of upper gastrointestinal surgery; and who had a treatment history with drugs that affect the function of upper gastrointestinal tract within the past 3 months were also excluded. Finally, the data from 1827 patients (1009 males, mean age 45.1 years) were included in the analysis (Fig. 1). The Institutional Review Board of Ajou University Hospital approved the study protocol (AJIRB-MED-MDB13-169).

\section{Questionnaires and Symptom Subgroups}

Demographic information, medication history, and upper gastrointestinal symptoms were evaluated using the questionnaire made for this study. To evaluate "typical reflux symptoms," "epigastric pain syndrome (EPS)-related symptoms," and "postprandial distress syndrome (PDS)-related symptoms," 6 symptoms (acid regurgitation, heartburn, epigastric burning, epigastric pain, postprandial fullness, and early satiation) were assessed. The symptom frequency within the past 3 months was evaluated as follows; never, less than once per week, and at least once per week. Each symptom was considered to be present if it had occurred at least once per week within the past 3 months. Acid regurgitation was defined as the reflux of a sour liquid from the stomach into the throat. Heartburn was defined as a burning sensation in the chest. Epigastric burning was defined as a burning sensation in the center of the upper abdomen or epigastrium. Epigastric pain was defined as pain in the center of the upper abdomen or epigastrium. Postprandial fullness was defined as an uncomfortable sensation after a meal, such as prolonged stasis of food in the stomach. Early satiation was defined as a feeling of fullness after eating a small amount of food, causing inability to finish a normal-sized meal. In the analysis, these symptoms were categorized into 3 subgroups as follows: typical reflux symptoms (heartburn and/or acid regurgitation), EPS-related symptoms (epigastric pain and/or epigastric burning), and PDS-related symptoms (postprandial fullness and/or early satiation). ${ }^{3}$

\section{Endoscopic Classification of Atrophic Gastritis}

The endoscopists that performed EGD at the Health Promotion Center of Ajou University Hospital were all specialists in the field of gastrointestinal endoscopy. Before the start of the study, they received education and training regarding the endoscopic classification system suggested by Kimura et al, ${ }^{13}$ and Suzuki and Moayyedi ${ }^{14}$ (Fig. 2). The diagnosis of atrophic area was based on a change that displayed discoloration with or without transparency of submucosal blood vessels. First, the extent or of atrophy in the stomach was divided into 2 types, a closed type (C-type) and an open type (O-type). If the atrophic border was located on the lesser curvature of the stomach, it was defined as C-type. Subsequently, C-type was subdivided according to the point at which the atrophic border locates: $\mathrm{C} 1$, confined to the antrum; C2, the lesser curvature of the lower corpus; or C3, the lesser curvature of the middle and upper corpus. If the atrophic border was shifted orally and did not exist on the lesser curvature, it was defined as O-type. The border in O-type extended along the anterior and posterior walls of the gastric corpus. The $\mathrm{C} 0$ indicates chronic gastritis with no or little atrophic change in the stomach that did not meet the criteria of $\mathrm{C} 1, \mathrm{C} 2, \mathrm{C} 3$, and $\mathrm{O}$. Sequential transition from $\mathrm{C} 0$ to any pattern from $\mathrm{C} 1$ to $\mathrm{O}$ means an extension of the atrophic area. For the analysis, these endoscopic subtypes were categorized into 3 groups as follows; the gastritis with no or little atrophy (group A: $\mathrm{C} 0$ ), the gastritis with atrophy mainly in the antrum (group B: $\mathrm{C} 1$ and $\mathrm{C} 2$ ), and the gastritis with atrophy in the large area of the corpus (group C: C3 and $\mathrm{O}$ ) (Fig. 3). The EGD findings of all subjects included in

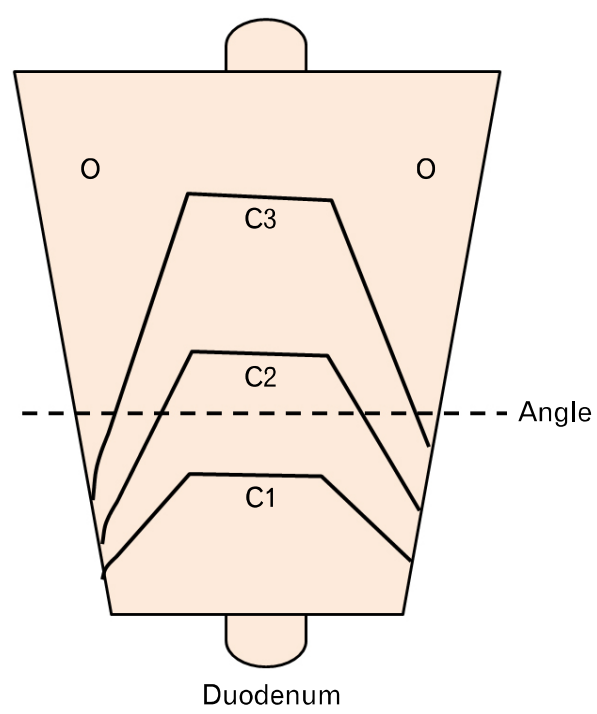

Figure 2. The classification of atrophic patterns in the stomach suggested by Kimura et al, ${ }^{13}$ and Suzuki and Moayyedi. ${ }^{14}$ This classification divides the extent of atrophy into a closed type (C-type) and an open type (O-type). 


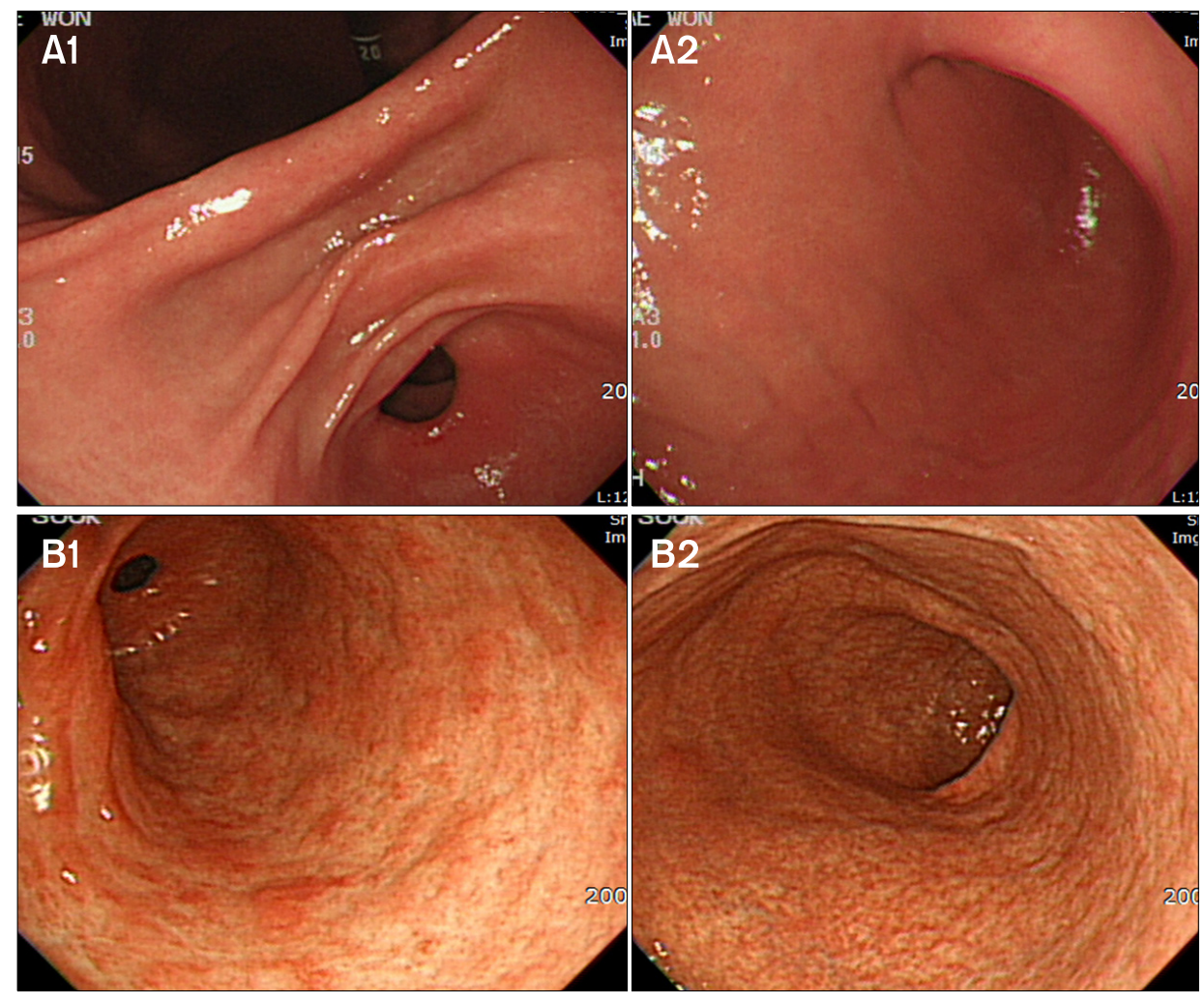

Figure 3. Endoscopic findings indicating the absence of atrophy in the antrum (A1) and corpus (A2), and the presence of atrophy in the antrum (B1) and corpus (B2).

the analysis were reassessed by 4 endoscopists (S.H.C., E.K., M.J.Y., and S.H.R.) who were blinded to the information of the subjects, and categorized into 3 groups. Inter-observer and intra-observer agreements (kappa values) were 0.68 and 0.89 , respectively.

\section{Statistical Methods}

Data are expressed as means \pm standard deviations (SDs). Continuous variables were compared using Student's $t$ test or ANOVA. Chi-square test was applied to compare categorical variables between groups. Multivariate analysis and calculation of odds ratio were performed using the binary logistic regression analysis. Statistical analyses were conducted using SPSS version 18.0 (IBM Corp, Armonk, NY, USA). A $P$-value $<0.05$ was taken as statistically significant.

\section{Results}

\section{Baseline Characteristics of the Subjects}

Out of the 1827 subjects included in the analysis, 1009 (55.2\%) were males. Their mean age was $45.1 \pm 9.8$ years. The subtypes of atrophic gastritis in the study subjects were as follows;
Table 1. Baseline Characteristics of the Study Subjects $(\mathrm{N}=1827)$

\begin{tabular}{|c|c|}
\hline Characteristics & \\
\hline \multicolumn{2}{|l|}{ Gender } \\
\hline Male (n [\%]) & $1009(55.2)$ \\
\hline Female (n [\%]) & $818(44.8)$ \\
\hline Age (mean $\pm \mathrm{SD}, \mathrm{yr})$ & $45.1 \pm 9.8$ \\
\hline Current smokers (n [\%]) & $372(20.4)$ \\
\hline Current alcohol consumers (n [\%]) & $1137(62.2)$ \\
\hline \multicolumn{2}{|l|}{ Atrophic gastritis subgroups } \\
\hline $\mathrm{C} 0(\mathrm{n}[\%])$ & $1218(66.7)$ \\
\hline $\mathrm{C} 1(\mathrm{n}[\%])$ & $189(10.3)$ \\
\hline $\mathrm{C} 2(\mathrm{n}[\%])$ & $203(11.1)$ \\
\hline C3 (n [\%]) & $106(5.8)$ \\
\hline \multicolumn{2}{|l|}{$\mathrm{O}(\mathrm{n}[\%])$} \\
\hline Symptom subgroups (n [\%]) & $111(6.1)$ \\
\hline Typical reflux symptoms & $191(10.5)$ \\
\hline EPS-related symptoms & $361(19.8)$ \\
\hline PDS-related symptoms & $296(16.2)$ \\
\hline
\end{tabular}

EPS, epigastric pain syndrome; PDS, postprandial distress syndrome.

$\mathrm{C} 0(\mathrm{n}=1218,66.7 \%), \mathrm{C} 1(\mathrm{n}=189,10.3 \%), \mathrm{C} 2(\mathrm{n}=203$, $11.1 \%), \mathrm{C} 3(\mathrm{n}=106,5.8 \%)$, and $\mathrm{O}(\mathrm{n}=111,6.1 \%)$. The subgroups of atrophic gastritis were as follows: group A ( $\mathrm{n}=1218$, $66.7 \%)$, group $B(n=392,21.4 \%)$, and group $C(n=217$, $11.9 \%)$. The proportion of current smokers and current alcohol 
drinkers was $20.4 \%$ and $62.2 \%$, respectively. Typical reflux, EPS-related, and PDS-related symptoms were present in 191 (10.5\%), 361 (19.8\%), and $296(16.2 \%)$ individuals, respectively (Table 1).

\section{Comparisons Among the Subgroups of Atrophic Gastritis}

Characteristics of the atrophic gastritis subgroups are shown in Table 2. The proportion of males was significantly greater in group B, but not in group C, compared with group A. The mean age of group $\mathrm{C}$ was significantly higher than that of group $\mathrm{A}$ and that of group B. The proportion of current smokers and current alcohol consumers was significantly lower in group C, compared with group A. The prevalence of each symptom subgroup such as typical reflux, EPS-related and PDS-related symptoms did not significantly differ among the atrophic gastritis subgroups (Table 2).

\section{Comparisons Among the Subgroups of Atrophic Gastritis in Males}

The mean age of group $C$ was significantly higher than that of group A and that of group B. The proportion of current smokers and current alcohol consumers was significantly lower in group C, compared with group A and group B. The prevalence of typical reflux symptoms and EPS-related symptoms did not significantly differ among the atrophic gastritis subgroups. PDSrelated symptoms were significantly more prevalent in group $\mathrm{C}$ than in group A and in group B (Table 3). Multivariate logistic regression analysis of group $\mathrm{A}$ (reference group) and group $\mathrm{C}$ revealed that older age (OR, 1.140; 95\% CI, 1.108-1.173; $P<$ 0.001 ) was independently associated with group $\mathrm{C}$ (data not shown). In multivariate logistic regression analysis of group $\mathrm{B}$ (reference group) and group $\mathrm{C}$ revealed that older age (OR, 1.032 [95\%CI: 1.006-1.059]; $P=0.015)$ and the presence of PDS-related symptoms (OR, 2.123; 95\% CI, 1.090-4.136; $P=$ 0.027 ) were independently associated with group C (Table 4 ).

\section{Comparisons Among the Subgroups of Atrophic Gastritis in Females}

The mean age of group $C$ was significantly higher than that of group A and that of group B. There was no significant difference in the proportion of current smokers among the atrophic gastritis subgroups. The proportion of current alcohol consumers was significantly lower in group C, compared with group A and group B. The prevalence of typical reflux symptoms and

Table 2. Comparisons Among the Subgroups of Atrophic Gastritis

\begin{tabular}{lcrrr}
\hline & $\begin{array}{c}\mathrm{C} 0 \\
(\mathrm{n}=1218)\end{array}$ & $\begin{array}{c}\mathrm{C} 1 \text { and C2 } \\
(\mathrm{n}=394)\end{array}$ & $\begin{array}{c}\mathrm{C} 3 \text { and } \mathrm{O} \\
(\mathrm{n}=215)\end{array}$ & $P$-value \\
\hline Male (n [\%]) & $653(53.6)$ & $246(62.4)$ & $110(50.9)$ & 0.002 \\
Age (mean + SD, yr) & $42.2 \pm 8.4$ & $50.0 \pm 9.5$ & $53.1 \pm 10.2$ & $<0.001$ \\
Current smokers (n [\%]) & $259(21.3)$ & $82(20.8)$ & $31(14.4)$ & 0.060 \\
Current alcohol consumers (n [\%]) & $789(64.8)$ & $242(61.4)$ & $106(49.3)$ & $<0.001$ \\
Typical reflux symptoms (n [\%]) & $132(10.8)$ & $44(11.2)$ & $15(7.0)$ & 0.188 \\
EPS-related symptoms (n [\%]) & $243(20.0)$ & $81(20.6)$ & $37(17.2)$ & 0.539 \\
PDS-related symptoms (n [\%]) & $203(16.7)$ & $53(13.5)$ & $40(18.6)$ & 0.216 \\
\hline
\end{tabular}

EPS, epigastric pain syndrome; PDS, postprandial distress syndrome.

Table 3. Comparisons Among the Subgroups of Atrophic Gastritis in Males

\begin{tabular}{lccrr}
\hline & $\begin{array}{c}\mathrm{C} 0 \\
(\mathrm{n}=653)\end{array}$ & $\begin{array}{c}\mathrm{C} 1 \text { and } \mathrm{C} 2 \\
(\mathrm{n}=246)\end{array}$ & $\begin{array}{c}\mathrm{C} 3 \text { and } \mathrm{O} \\
(\mathrm{n}=110)\end{array}$ & $P$-value \\
\hline Age (mean $\pm \mathrm{SD}, \mathrm{yr})$ & $42.4 \pm 7.8$ & $49.7 \pm 9.0$ & $52.6 \pm 9.6$ & $<0.001$ \\
Current smokers (n [\%]) & $250(38.3)$ & $79(32.1)$ & $28(25.5)$ & 0.016 \\
Current alcohol consumers (n [\%]) & $552(84.5)$ & $185(75.2)$ & $79(71.8)$ & $<0.001$ \\
Typical reflux symptoms (n [\%]) & $67(10.3)$ & $24(9.8)$ & $6(5.5)$ & 0.289 \\
EPS-related symptoms (n [\%]) & $113(17.3)$ & $33(13.4)$ & $20(18.2)$ & 0.333 \\
PDS-related symptoms (n [\%]) & $90(13.8)$ & $24(9.8)$ & $22(20.0)$ & 0.030 \\
\hline
\end{tabular}

EPS, epigastric pain syndrome; PDS, postprandial distress syndrome. 
Table 4. Multivariate Logistic Regression Analysis of Group B (Atrophy Mainly in the Antrum; Reference Group) and Group C (Atrophy in the Large Area of the Corpus) in Males

\begin{tabular}{lcccc}
\hline \multicolumn{1}{c}{ Parameters } & & & \multicolumn{2}{c}{$95 \%$ CI } \\
\cline { 3 - 4 } Age & $P$-value & OR & Lower limit & Upper limit \\
Current smokers & 0.015 & 1.032 & 1.006 & 1.059 \\
Current alcohol consumers & 0.314 & 0.765 & 0.454 & 1.289 \\
Typical reflux symptoms & 0.825 & 0.942 & 0.555 & 1.599 \\
EPS-related symptoms & 0.080 & 0.416 & 0.156 & 1.109 \\
PDS-related symptoms & 0.234 & 1.495 & 0.771 & 2.899 \\
\hline
\end{tabular}

OR, odds ratio; CI, confidence interval; EPS, epigastric pain syndrome; PDS, postprandial distress syndrome.

Table 5. Comparisons Among the Subgroups of Atrophic Gastritis in Females

\begin{tabular}{lcccc}
\hline & $\begin{array}{c}\mathrm{C} 0 \\
(\mathrm{n}=565)\end{array}$ & $\begin{array}{c}\mathrm{C} 1 \text { and C2 } \\
(\mathrm{n}=146)\end{array}$ & $\begin{array}{c}\mathrm{C} 3 \text { and } \mathrm{O} \\
(\mathrm{n}=107)\end{array}$ & $P$-value \\
\hline Age (mean $\pm \mathrm{SD}, \mathrm{yr})$ & $41.9 \pm 9.0$ & $50.6 \pm 10.3$ & $53.5 \pm 10.8$ & $<0.001$ \\
Current smokers (n [\%]) & $9(1.6)$ & $3(2.1)$ & $3(2.8)$ & 0.725 \\
Current alcohol consumers (n [\%]) & $237(41.9)$ & $57(39.0)$ & $27(25.2)$ & 0.005 \\
Typical reflux symptoms (n [\%]) & $65(11.5)$ & $20(13.7)$ & $9(8.4)$ & 0.425 \\
EPS-related symptoms (n [\%]) & $130(23.0)$ & $48(32.9)$ & $17(15.9)$ & 0.005 \\
PDS-related symptoms (n [\%]) & $113(20.0)$ & $29(19.9)$ & $18(16.8)$ & 0.762 \\
\hline
\end{tabular}

EPS, epigastric pain syndrome; PDS, postprandial distress syndrome.

PDS-related symptoms did not significantly differ among the atrophic gastritis subgroups. EPS-related symptoms were significantly more prevalent in group B than in group A and group $\mathrm{C}$ (Table 5). Multivariate logistic regression analysis of group A (reference group) and group $\mathrm{B}$ revealed that older age (OR, 1.104; 95\% CI, 1.080-1.129; $P<0.001)$, current alcohol consumers (OR, 1.620; 95\% CI, 1.054-2.490; $P=0.028)$ and the presence of EPS-related symptoms (OR, 1.723; 95\% CI, $1.067-2.781 ; P=0.026)$ were independently associated with group B (Table 6). In multivariate logistic regression analysis of group $\mathrm{C}$ (reference group) and group $\mathrm{B}$, the presence of EPS-related symptoms (OR, 2.571; 95\% CI, 1.319-5.025; $P=0.006)$ was independently associated with group B (Table 7 ).

\section{Discussion}

Chronic gastritis is believed to affect a considerable number of people, particularly in countries where $H$. pylori infection is prevalent. As people get older this condition becomes more common. Chronic mucosal inflammation in the stomach may lead to abnormalities in gastric motor and sensory function. ${ }^{14-16}$ In addition, chronic gastritis results in gastric atrophy, affecting gastric secretion of acid, somatostatin, gastrin, and ghrelin. ${ }^{14}$ These abnormalities might generate dyspeptic symptoms in some patients with functional dyspepsia. Although $H$. pylori gastritis has been suggested to be a cause involved in the genesis of dyspeptic symptoms, ${ }^{14-16}$ the clinical evidence regarding the relationship between atrophic gastritis and dyspeptic symptoms is lacking. The results of the present study can provide the clinical evidence suggesting that the extent or grade of atrophic gastritis can affect the generation of specific dyspeptic symptoms. This influence was different according to the gender.

A variety of conditions and medications can induce inflammation of the stomach, leading to chronic gastritis. Among them, the main cause of chronic gastritis is known to be infection from a bacterium called $H$. pylori. The seroprevalence of $H$. pylori infection is still high in South Korea, being $54.4 \%$ in $2013 .^{17}$ This high infection rate contributes to the high prevalence of atrophic gastritis in the general population of South Korea. The influence of gastric atrophy on dyspeptic symptoms remains unclear yet. Our results demonstrated that male subjects who had atrophic gastritis involved in the large area of the corpus were independently associated with a higher prevalence of PDS-related symptoms and female subjects who had atrophic gastritis involved 
Table 6. Multivariate Logistic Regression Analysis of Group A (No or Little Atrophy; Reference Group) and Group B (Atrophy Mainly in the Antrum) in Females

\begin{tabular}{lcccc}
\hline \multicolumn{1}{c}{ Parameters } & & & \multicolumn{2}{c}{$95 \%$ CI } \\
\cline { 3 - 4 } Age & $P$-value & OR & Lower limit & Upper limit \\
Current smokers & 0.001 & 1.104 & 1.080 & 1.129 \\
Current alcohol consumers & 0.757 & 0.790 & 0.178 & 3.517 \\
Typical reflux symptoms & 0.028 & 1.620 & 1.054 & 2.490 \\
EPS-related symptoms & 0.893 & 0.957 & 0.506 & 1.812 \\
PDS-related symptoms & 0.026 & 1.723 & 1.067 & 2.781 \\
\hline
\end{tabular}

OR, odds ratio; CI, confidence interval; EPS, epigastric pain syndrome; PDS, postprandial distress syndrome.

Table 7. Multivariate Logistic Regression Analysis of Group C (Atrophy in the Large Area of the Corpus; Reference Group) and Group B (Atrophy Mainly in the Antrum) in Females

\begin{tabular}{lcccc}
\hline \multicolumn{1}{c}{ Parameters } & & \multicolumn{2}{c}{ 95\% CI } & UR \\
\cline { 3 - 4 } & P-value & Lower limit & 1.003 \\
Age & 0.082 & 0.976 & 0.951 & 4.310 \\
Current smokers & 0.810 & 0.815 & 0.154 & 3.125 \\
Current alcohol consumers & 0.075 & 1.718 & 0.947 & 3.906 \\
Typical reflux symptoms & 0.337 & 1.565 & 0.628 & 5.025 \\
EPS-related symptoms & 0.006 & 2.571 & 1.319 & 1.908 \\
PDS-related symptoms & 0.861 & 0.938 & 0.462 & \\
\hline
\end{tabular}

OR, odds ratio; CI, confidence interval; EPS, epigastric pain syndrome; PDS, postprandial distress syndrome.

mainly in the antrum were independently associated with a higher prevalence of EPS-related symptoms. PDS is believed to be associated with delayed gastric emptying or impaired proximal gastric accommodation to a meal. ${ }^{3}$ Gastric atrophy in the large area of the corpus can lead to the loss of parietal cells, chief cells, and ghrelin cells located in the gastric corpus. This might reduce the secretion of acid, pepsin, and ghrelin. It remains to be explored whether these alterations induced by advanced atrophy of the gastric corpus and fundus cause gastric motor dysfunction associated with PDS. Since D cells in the antrum produces somatostatin inhibiting gastric acid, gastric acid secretion might be increased by gastric atrophy involved mainly in the antrum. The pathophysiological mechanisms behind EPS are not fully understood. However, visceral hypersensitivity, such as hypersensitivity to gastric distension, gastric acid, or nutrients, is a plausible mechanism. ${ }^{18}$ In addition, epigastric pain or burning sensation may be associated with gastroesophageal reflux. ${ }^{19,20}$ Therefore, gastric acid hypersecretion might result in EPS-related symptoms. These findings suggest that the extent or grade of atrophic gastritis can be involved in the generation of specific dyspeptic symptoms.
Proton pump inhibitors are effective for the treatment of dyspepsia in some patients with functional dyspepsia. ${ }^{4,5}$ However, the mechanism underlying this beneficial effect still remains unestablished. Although gastric acid hypersecretion, caused by hypergastrinemia, hyperhistaminemia, or an unknown etiology, may be associated with the effect of proton pump inhibitors, these conditions are not common. Furthermore, the excessive secretion of gastric acid can cause peptic ulcer disease and gastroesophageal reflux disease as well as functional dyspepsia. Studies have reported inconsistent results regarding the levels of gastric acid secretion in patients with functional dyspepsia. $6,10,11$ Actually, evidence that gastric hyperchlorhydria is one of the major pathophysiologic mechanisms of functional dyspepsia is lacking. Moreover, atrophic gastritis is common in the general population of South Korea and Japan where H. pylori is highly prevalent. Acid secretion levels may be influenced by the extent or grade of gastric atrophy. Advanced atrophic gastritis in the gastric corpus may result in gastric hypochlorhydria. ${ }^{21} \mathrm{~A}$ recent study from Japan revealed that the total symptom scores and dysmotility-related symptom scores were significantly higher in female subjects with gastric hypochlorhydria compared with the 
non-hypochlorhydria group. ${ }^{22}$ They presumed that hypochlorhydria-related abnormalities in digestion, absorption, and motility might be responsible for this observation. The reason why this finding was observed only in female subjects was not mentioned in that study. Unlike the previous study from Japan, we observed a significantly higher prevalence of PDS-related symptoms in male subjects with atrophic gastritis involved in the large area of the corpus, and a significantly higher prevalence of EPD-related symptoms in female subjects with atrophic gastritis involved mainly in the antrum. This gender difference cannot be explained clearly, requiring further study.

H. pylori infection is the main cause of chronic gastritis in humans, particularly in South Korea. Atrophic gastritis is a quite common consequence of $H$. pylori gastritis in South Korea and Japan. ${ }^{23}$ It will develop on a multifactorial basis including dietary factors and aging. ${ }^{24}$ Autoimmune mechanisms are very rare in South Korea and of minor significance. Therefore, it is likely of no problem in interpreting the results that $H$. pylori test was not performed in the present study. We did not aim to elucidate the association of $H$. pylori gastritis with specific dyspeptic symptoms, but the association of atrophic gastritis with specific dyspeptic symptoms. The pattern or type of $H$. pylori gastritis is variable, and difficult to study its relationship with symptoms or pathophysiologic mechanisms. Therefore, in the present study, it is not essential to know the status of $H$. pylori infection. The pathophysiological mechanisms underlying $H$. pylori-associated dyspepsia have not yet been established. Inconsistent results might be related to variable manifestations of $H$. pylori infection in the stomach. When $H$. pylori infects the antrum only, slight hypergastrinemia with acid hypersecretion occurs. ${ }^{25}$ When $H$. pylori infection spreads to oxyntic mucosa, it induces atrophy of the gastric corpus, which results in reduced secretion of gastric acid. ${ }^{26}$ The former is similar to atrophic gastritis mainly in the antrum (group B), whereas the latter is analogous to atrophic gastritis in the large area of the gastric corpus (group C). Differences in the involved area of atrophic gastritis are likely to induce different abnormalities in gastric function, leading to the generation of different dyspeptic symptoms. However, the reason why there is a gender difference in the results cannot be explained clearly. Given that diverse pathogenetic factors and pathophysiologic mechanisms are involved in functional dyspepsia, the difference in the susceptible pathogenetic factors or pathophysiologic mechanisms between males and females might contribute to this gender difference. In keeping with this presumption, a recent animal study demonstrated gender differences in the involvement of opioids in psychological stress-induced visceral analgesia; specifically, it was mainly naloxone-dependent in females, but naloxone-independent in males. ${ }^{27}$

The current study has several strengths. First, it was of a prospective design and included consecutive study subjects. Second, the sample size was large, providing sufficient statistical power for analysis. Third, individuals undergoing health checkups are appropriate for studying the relationship between specific subtypes of dyspeptic symptoms and endoscopic subgroups of atrophic gastritis because they may or may not have upper gastrointestinal symptoms. EGD is performed routinely in health-checkup programs in South Korea because of the high prevalence of gastric cancer. Nevertheless, the current study has several limitations. First, the symptoms were not checked daily using symptom diaries; instead, symptoms were assessed using subjective recall. Second, other factors affecting a symptom manifestation, such as the level of stress and psychological factors, were not evaluated. Third, the levels of gastric acid, pepsin, and ghrelin secretion were not checked. Forth, gastric motor and sensory function associated with major pathophysiologic mechanisms of functional dyspepsia were not assessed.

In conclusion, atrophic gastritis involved in the large area of the gastric corpus appears to increase the prevalence of PDS-related symptoms in males, whereas atrophic gastritis involved mainly in the antrum appears to enhance the development of EPS-related symptoms in females. These findings suggest that the extent of atrophic gastritis affects the generation of specific dyspeptic symptoms in a gender-dependent manner. The relationship between the extent of atrophic gastritis and the pathophysiological mechanisms of PDS or EPS requires further investigation.

\section{References}

1. Talley NJ , Vakil NB, Moayyedi P. American Gastroenterological Association technical review on the evaluation of dyspepsia. Gastroenterology 2005;129:1756-1780.

2. Lee SY, Lee KJ, Kim SJ, Cho SW. Prevalence and risk factors for overlaps between gastroesophageal reflux disease, dyspepsia, and irritable bowel syndrome: a population-based study. Digestion 2009;79: 196-201.

3. Tack J, Talley N, Camilleri M, Holtmann G, Hu P, Malagelada JR, Stanghellini V. Functional gastroduodenal disorders. Gastroenterology 2006;130:1466-1479.

4. Veldhuyzen van Zanten SJ, Chiba N, Armstrong D, et al. A randomized trial comparing omeprazole, ranitidine, cisapride, or placebo in Helicobacter pylori negative, primary care patients with dyspepsia: the 
CADET-HN study. Am J Gastroenterol 2005;100:1477-1488.

5. van Zanten SV, Flook N, Talley NJ, et al. One-week acid suppression trial in uninvestigated dyspepsia patients with epigastric pain or burning to predict response to 8 weeks' treatment with esomeprazole: a randomized, placebo-controlled study. Aliment Pharmacol Ther 2007;26:665-672.

6. el-Omar E, Penman I, Ardill JE, McColl KE. A substantial proportion of non-ulcer dyspepsia patients have the same abnormality of acid secretion as duodenal ulcer patients. Gut 1995;36:534-538.

7. Miwa $\mathrm{H}$, Nakajima K, Yamaguchi K, et al. Generation of dyspeptic symptoms by direct acid infusion into the stomach of healthy Japanese subjects. Aliment Pharmacol Ther 2007;26:257-264.

8. Misra SP, Broor SL. Is gastric acid responsible for the pain in patients with essential dyspepsia? J Clin Gastroenterol 1990;12:624-627.

9. George AA, Tsuchiyose M, Dooley CP. Sensitivity of the gastric mucosa to acid and duodenal contents in patients with nonulcer dyspepsia. Gastroenterology 1991;101:3-6.

10. Tucci A, Corinaldesi R, Stanghellini V, et al. Helicobacter pylori infection and gastric function in patients with chronic idiopathic dyspepsia. Gastroenterology 1992;103:768-774.

11. Nyrén O. Secretory abnormalities in functional dyspepsia. Scand J Gastroenterol 1991;26(suppl 182):25-28.

12. Sipponen P. Update on the pathologic approach to the diagnosis of gastritis, gastric atrophy, and Helicobacter pylori and its sequelae. J Clin Gastroenterol 2001;32:196-202.

13. Kimura K, Satoh K, Ido K, Taniguchi Y, Takimoto T, Takemoto T. Gastritis in the Japanese stomach. Scand J Gastroenterol 1996; 31(suppl 214):17-20.

14. Suzuki H, Moayyedi P. Helicobacter pylori infection in functional dyspepsia. Nat Rev Gastroenterol Hepatol 2013;10:168-174.

15. Suzuki H, Nishizawa T, Hibi T. Can Helicobacter pylori-associated dyspepsia be categorized as functional dyspepsia? J Gastroenterol Hepatol 2011;26(suppl 3):42-45.

16. Sugano K. Should we still subcategorize Helicobacter pylori-associated dyspepsia as functional disease? J Neurogastroenterol Motil 2011; 17:366-371.

17. Lim SH, Kwon JW, Kim N, et al. Prevalence and risk factors of Helicobacter pylori infection in Korea: nationwide multicenter study over 13 years. BMC Gastroenterol 2013;13:104.

18. Lee KJ, Tack J. Duodenal implications in the pathophysiology of functional dyspepsia. J Neurogastroenterol Motil 2010;16:251-257.

19. Tack J, Caenepeel P, Arts J, Lee KJ, Sifrim D, Janssens J. Prevalence of acid reflux in functional dyspepsia and its association with symptom profile. Gut 2005;54:1370-1376.

20. Xiao YL, Peng S, Tao J, et al. Prevalence and symptom pattern of pathologic esophageal acid reflux in patients with functional dyspepsia based on the Rome III criteria. Am J Gastroenterol 2010;105: 2626-2631.

21. Sipponen P, Kekki M, Seppälä K, Siurala M. The relationships between chronic gastritis and gastric acid secretion. Aliment Pharmacol Ther 1996;10(suppl 1):103-118.

22. Iwai $\mathrm{W}$, Abe $\mathrm{Y}$, Iijima $\mathrm{K}$, et al. Gastric hypochlorhydria is associated with an exacerbation of dyspeptic symptoms in female patients. J Gastroenterol 2013;48:214-221.

23. Ito S, Azuma T, Murakita H, et al. Profile of Helicobacter pylori cytotoxin derived from two areas of Japan with different prevalence of atrophic gastritis. Gut 1996;39:800-806.

24. Kapadia CR. Gastric atrophy, metaplasia, and dysplasia: a clinical perspective. J Clin Gastroenterol 2003;36(5 suppl):S29-S36.

25. Levi S, Beardshall K, Haddad G, Playford R, Ghosh P, Calam J. Campylobacter pylori and duodenal ulcers: the gastrin link. Lancet 1989;1:1167-1168.

26. Waldum HL, Hauso $\varnothing$, Fossmark R. The regulation of gastric acid secretion—clinical perspectives. Acta Physiol 2014;210:239-256

27. Larauche M, Mulak A, Kim YS, Labus J, Million M, Taché Y. Visceral analgesia induced by acute and repeated water avoidance stress in rats: sex difference in opioid involvement. Neurogastroenterol Motil 2012;24:1031-e547. 